\title{
Phototherapy: a simple and safe treatment for neonatal jaundice
}

\begin{abstract}
Phototherapy: A simple and safe treatment for Neonatal Jaundice. Jaundice is a common finding in premature and full term newborns. Phototherapy has been widely used in the management of Neonatal unconjugated Hyperbilirubinemia for over five decades. Phototherapy devices include Fluorescent, Halogen, Fiberoptic or Light-Emitting Diode light sources. Safety issues and possible complications of phototherapy are discussed. It is a non invasive, safe and easily available therapy worldwide. This review will focus on the use of phototherapy in newborn nurseries.
\end{abstract}

Keywords: phototherapy, hyperbilirubinemia, light treatment, newborn
Volume 2 Issue 3 - 2015

\author{
Adel M Zauk \\ Department of Pediatrics, NY Medical College, USA \\ Correspondence: Adel M Zauk, Chief of Neonatology, \\ Director of Nurseries, St. Joseph $\square$ s Children $\square$ s Hospital, \\ Adjunct Associate Professor of Pediatrics, NY Medical College, \\ 703 Main Street, Suite A24I8, Paterson, NJ 07503, USA, Tel (973) \\ 754-2555, Fax (973) 754-2567, Email Zauka@sjhmc.org
}

Received: December 02, 2014 | Published: May 15, 2015

\section{Introduction}

In 1958, Cremer et al., ${ }^{1}$ demonstrated that serum bilirubin concentrations fall faster in premature infants exposed to sunlight or blue fluorescent bulbs. However, phototherapy wasn't commonly used until 1968, when Lucey et al., ${ }^{2}$ conducted the first large clinical trial using daylight fluorescent tubes for the treatment of jaundice. Today, it is commonly applied in most nurseries throughout the world in order to prevent kernicterus. Risk factors for the development of severe jaundice and kernicterus include asphyxia, sepsis, acidosis, hypoalbuminemia and hemolysis. ${ }^{3}$ The goal of phototherapy is to avoid an exchange transfusion. Any baby placed under phototherapy requires a history and physical examination, as well as laboratory screening for pathologic jaundice. Bilirubin is one of the few substances in the body that absorbs light. Under lights, normal bilirubin (4Z, 15Z-bilirubin) undergoes photoisomerization through the skin to form photobilirubin and lumirubin. These photo products are water-soluble, bypassing the liver's conjugating system, and are rapidly excreted in both urine and bile. Maintenance of adequate hydration and good urine output enhances the efficacy of phototherapy.

\section{Neonatal jaundice}

Jaundice is the visible yellow appearance of the skin that occurs with chemical hyperbilirubinemia. It happens in adults with serum bilirubin greater than $2 \mathrm{mg} / \mathrm{dl}$, and in neonates with serum bilirubin greater than $5 \mathrm{mg} / \mathrm{dl}$. Bilirubin is formed by the breakdown of heme. Newborns have differences in bilirubin production and elimination leading to a rise in bilirubin levels referred to as physiological hyperbilirubinemia that is present in as many as $60 \%$ of all normal neonates in the first several days after birth. Pathological newborn hyperbilirubinemia can be caused by increased bilirubin production such as hemolysis or decreased bilirubin clearance such as prematurity. Effective treatments for high bilirubin concentration in infants include intravenous gamma-globulin ${ }^{3}$ phototherapy and exchange transfusion. The exact total serum bilirubin level, at which phototherapy should be started depends on several risk factors including prematurity, age of the infant and other risk factors. ${ }^{4}$

\section{Indications}

To help pediatricians in their decisions on when to start phototherapy, the American Academy of Pediatrics, published in 2011 guidelines on the management of hyperbilirubinemia in newborns 35 or more weeks gestation. ${ }^{5}$ Maisels et al., ${ }^{6}$ in 2012 provided an approach (Table 1) to use phototherapy and exchange transfusion in preterm infants less than 35 weeks of gestation. The AAP committees on fetus and newborn guidelines were evidence-based but Maisels et al., ${ }^{6}$ recommendations are consensus-based. Infants with congenital erythropoietic porphyria are contraindications to the use of phototherapy.

Table I Suggested use of phototherapy and exchange transfusion in preterm infants $<35$ weeks gestation age Maisels et al.,

\begin{tabular}{lll}
\hline & Phototherapy & Exchange Transfusion \\
\hline $\begin{array}{l}\text { Gestational } \\
\text { Age (week) }\end{array}$ & $\begin{array}{l}\text { Initiate Phototherapy } \\
\text { Total Serum Bilirubin } \\
\text { (mg dl-I) }\end{array}$ & $\begin{array}{l}\text { Total Serum Bilirubin } \\
\text { (mg dl-I) }\end{array}$ \\
\hline$<280 / 7$ & 6-May & I4-Nov \\
$280 / 7-296 / 7$ & 8-Jun & 14-Dec \\
$300 / 7-316 / 7$ & 10-Aug & $13-16$ \\
$320 / 7-336 / 7$ & 12-Oct & $15-18$ \\
$340 / 7-346 / 7$ & 14-Dec & $17-19$ \\
\hline
\end{tabular}

\section{Types of phototherapy}

The traditional phototherapy units using fluorescent tubes contain standard blue (Westinghouse F20T 12B), daylight (F20 T12D) and cool white (F20 T12CW) lamps. The most effective lights are those with a high energy output near the maximum absorption peak of bilirubin (450 to $460 \mathrm{~nm}$ ). ${ }^{7}$ Special blue lamps (Phillips TL 52/20W, Westinghouse 20watt F20 T12BB) are the most efficient for neonatal phototherapy because they have more than twice the energy output at $450 \mathrm{~mm}$ than the standard blue bulbs. Investigators using these special blue bulbs report they have achieved a more rapid reduction of serum bilirubin than with daylight or standard blue bulbs. ${ }^{8}$ However, the special blue bulbs have been found to cause nausea and dizziness among the nursery staff. A combination of four special blue lamps placed in the center of the phototherapy unit with two day light lamps on either side has been found to provide excellent irradiance without producing significant discomfort to staff members. Non-fluorescent halogen lamps (spotlights) produce a more intense light over a smaller surface but are more expensive than fluorescents. If they are placed closer than $50 \mathrm{~cm}$, halogen lamps unlike fluorescent bulbs incur the risk of burns to the infant. 
Light-Emitting Diode (LED) lights are now commercially available for use in the United States. ${ }^{9}$ The Neo Blue LED systems incorporate optimal blue LED technology and are manufactured by Natus Medical Inc., San Carlos, CA, USA. Neo Blue LED's emit blue light in the $450-470 \mathrm{~nm}$ spectrum. They are the safest phototherapy devices available because they do not emit light in the ultraviolet and the infrared radiation range. The virtual absence of heat when delivering overhead Neo Blue phototherapy should be less likely to cause insensible water loss. ${ }^{10}$ Fiberoptic phototherapy systems first appeared on the market in 1989. They are widely considered to be equally as effective as and more convenient than overhead lights. Light is delivered from a halogen bulb (bulb life $=450$ hours) through a fiber optic cable and is emitted filtered from the sides and ends of fibers inside a plastic blanket which is protected by a disposable cover. Infants lie on the blanket or are held with the blanket wrapped around them, and the need for eye patches - otherwise required in neonatal phototherapy - is eliminated.

Technology currently provides the clinician with three different modes of phototherapy delivery: fiber optic, low intensity, and high intensity phototherapy. For low intensity phototherapy, overhead lamps are typically set at a distance of $50 \mathrm{~cm}$ from the patient. High intensity phototherapy has been defined by the American Academy of Pediatrics as a spectral irradiance of at least $30 \mathrm{MW}$ per square meter per nanometer. High-intensity phototherapy is achieved by using a unit with eight special blue lamps or Neo Blue LED systems $25 \mathrm{~cm}$ above the naked infant who is on a fiber optic phototherapy blanket in a bassinet, while wearing a tie-on surgeon's mask as a diaper. This method allows maximum skin exposure and achieves an irradiance as high as $50 \mathrm{uw} / \mathrm{cm}^{2} / \mathrm{nm}$.

However, as lamps are lowered close to the infant, there is an increase in the heterogeneity of irradiation, with a much greater increase at the center than at the periphery. Lining the bassinet with a white cloth produces greater homogeneity or irradiance and an increase in the amount of indirect reflected irradiance. Home phototherapy ${ }^{11}$ should be limited to otherwise healthy term infants who are older than 48hours with bilirubin levels between and 15 and $20 \mathrm{mg} / \mathrm{dl}$ and no hemolysis. Parents have to be able to monitor the baby's temperature and hydration status. Home visits by a nurse experienced in evaluating newborns are performed, with results of bilirubin levels available on a timely basis.

\section{Monitoring light intensity}

The energy output in the 425 to $475 \mathrm{~mm}$ range delivered to the patient by any source of light must be monitored every eight hours and recorded as spectral irradiance in micro-watts $/ \mathrm{cm}^{2} / \mathrm{nm}$. Measurement from all fluorescent, LED and halogen phototherapy lights should be done at the level of the abdominal skin of the newborn. A different sensor should be used with fiber optic phototherapy, and measurements are performed directly at the surface of the pad. Caution must be exercised in interpreting measurements from photometers or spectroradiometers, as different instruments provide readouts in varying units. According to current knowledge, there is a doseresponse relationship between bilirubin degradation and phototherapy intensity up to a reading of approximately $40 \mathrm{uw} / \mathrm{cm}^{2} / \mathrm{nm}$.

Fluorescent lamps decay with use and should not be left on until they burn out. If these lamps are kept adequately cool, their irradiance drops about 10 percent in the first hundred hours of use and 20 percent after 3,600hours. In contrast halogen lamps used in fiber optic devices or overhead spotlights, have a lifetime irradiation drop of less than a few percent. Therefore, measuring their output is unnecessary as these bulbs can burn out before needing replacement. It should also be noted that skin pigmentation does not reduce effectiveness of phototherapy.

\section{Safety issues and possible complications}

Current literature on phototherapy use provides a variety of safety considerations for the clinician. A Plexiglas shield should always be in position under the fluorescent bulbs. This shield acts as a filter for erythemogenic ultraviolet radiation (below $320 \mathrm{~mm}$ ) and protects in the event of lamp breakage. All phototherapy lights generate some heat, possibly resulting in overheating the incubator if the lights are too close to the top (two inches is the recommended air space). Because of potential for eye damage, ${ }^{12}$ both of the infant's eyes should be covered with correctly sized opaque patches. These patches can become displaced, obstruct the nares and cause apnea, so constant attention is necessary to avoid such a hazard. Eye shields may cause impairment of drainage of tears, corneal abrasion and eye infection. Eye patches should be removed at feeding time and changed at least daily. The infant's eyes should be examined every eight hours, and if purulent eye discharge is noted, swabs should be used for bacterial cultures.

Damage of the gonads ${ }^{13}$ during phototherapy is unlikely because the period of exposure is relatively short and gonads are shielded by the skin over the subcutaneous tissue. The infant's temperature needs to be monitored every two to three hours. Clinical assessment of skin color for jaundice or cyanosis is not as accurate once phototherapy has begun. Serum bilirubin levels should be monitored frequently during phototherapy on at least 24 hours after its cessation, in order to rule out the occurrence of significant rebound. In addition, oxygen saturation monitor probes must be shielded from phototherapy lights because light interferes with the accuracy of pulse oximetry measurements. ${ }^{14}$ Phototherapy units should be turn off during phlebotomy for bilirubin levels. Otherwise exposure of the blood to the light could reduce its level. Plastic heat shields should be removed because of decreased irradiance. Phototherapy should not be used for infants with obstructive jaundice as these infants might develop a reversible dark, grey-brown discoloration of the skin, serum and urine called "bronze baby syndrome. ${ }^{15}$

When using non-LED lights daily weight and close monitoring of intake and output may indicate a need for additional fluid requirement. To compensate for intestinal and insensible losses,${ }^{16}$ the percentage of fluid intake should be increased in an inverse ratio to the size of the infant (20 to 60 percent above maintenance). Studies have shown there is no difference in fluid loss between fiber optic and conventional phototherapy. During non-LED lights phototherapy, there is an increase in skin and muscle blood flow, insensible water loss, skin temperature, heart rate, and respiratory rate. These effects can be partially decreased by vigilant monitoring of vital signs every two to three hours and by covering the servo probe with a heat reflecting device. Phototherapy may produce a transient rash, transient loose green stools, lethargy, or abdominal distention. Recent studies have suggested that phototherapy is associated with childhood bronchial asthma ${ }^{17}$ and is a risk factor for insulin-dependent diabetes. ${ }^{18}$

\section{Conclusion}

Phototherapy is safe $\mathrm{e}^{19,20}$ inexpensive, efficient, and easy to use. With high intensity phototherapy, even severe hemolytic hyperbilirubinemia can be adequately controlled. ${ }^{21}$

\section{Phototherapy:}

i. Does require medical attention because of its potential toxicity and the risk for kernicterus. 
ii. Guidelines for the initiation and duration of phototherapy have been published.

\section{Acknowledgments}

None.

\section{Conflicts of interest}

Author declares there are no conflicts of interest.

\section{Funding}

None.

\section{References}

1. Cremer RJ, Parryman PW, Richards DH. Influence of light on the hyperbilirubinemia of infants. Lancet . 1958;1(7030):1094-1097.

2. Lucey J, Ferreiro M, Hewitt J. Prevention of hyperbilirubinemia of prematurity by phototherapy. Pediatrics. 1968;41(6):1047-1054.

3. Alpay F, Sarici SU, Okutan V, et al. High-dose intravenous immunoglobin therapy in neonatal immune jaundice. Acta Paediatr. 1999;88(2):216-219.

4. Johnson L, Bhutani VK, Karp K, et al. Clinical report from the pilot USA Kernicterus Registry (1992 to 2004). J Perinatal . 2009;29(suppl 1):S25-S45.

5. Bhutani VK, Committee on Fetus and Newborn, American Academy of Pediatrics. Phototherapy to Prevent Severe Neonatal Hyperbilirubinemia in the Newborn Infant 35 or More Weeks of Gestation. Pediatrics. 2011;128(4):e1046-e1052.

6. Maisels MJ, Watchko JF, Bhutani VK, et al. An approach to the management of Hyperbilirubinemia in the preterm infant less than 35 weeks of gestation. J Perinatology . 2012;32(9):660-664.

7. Weiss EM, Zimmerman SS. A tale of two hospitals: The evolution of phototherapy treatment for Neonatal Jaundice. Pediatrics. 2013;131(6):1032-1034.
8. Ennever JF, McDonagh AF, Speck WT. Phototherapy for neonatal jaundice: optimal wavelengths of light. J Pediatr. 1983;103(2):295-299.

9. Maisels MJ, McDonagh AF. Phototherapy for neonatal jaundice. $N$ Engl J Med. 2008;358(9):920-928.

10. Seidman DS, Moise J, Ergaz Z, et al. A new blue light-emitting phototherapy device: A prospective randomized controlled study. $J$ Pediatr. 2000;136(6):771-774.

11. Maisels MJ, Kring EA, DeRidder J. Randomized controlled trial of light emitting diode phototherapy. J Perinatol. 2007;27(9):565-567.

12. Eggert LD, Pollary RA, Folland DS, et al. Home Phototherapy of Neonatal Jaundice. Pediatrics. 1985;76(4):579-584.

13. Fok TF, Wong W, Cheung KL. Eye protection for newborns under phototherapy: comparison between a modified headbox and the conventional eye patches. Ann Trop Paediatr. 1997;17(4):349-354.

14. Koc H, Altunhan H, Dilsiz A, et al. Testicular changes in newborn rats exposed to phototherapy. Pediatr Dev Pathol. 1999;2(4):333-336.

15. Fouza SS, Priftis KN, Anthracoupoulos MB. Pulse oximetry in Pediatric Practice. Pediatrics. 2011;128(4):740-752.

16. Kopelman AE, Brown RS, Odell GB. The "Bronze" Baby Syndrome: A Complication of Phototherapy. J Pediatr. 1972;81(3):466-472.

17. Maayan-Metzger A, Yosipovitch G, Haddad E, et al. Transepidermal Water Loss and Skin Hydration in Preterm Infants During Phototherapy. Am J Perinatol . 2001;18(7):393-396.

18. Aspberg S, Dahlquist G, Kahan T, et al. Is neonatal phototherapy associated with an increased risk for hospitalized childhood bronchial asthma? Pediatr Allergy Immunol . 2007;18(4):313-319.

19. Dahlquist G, Kallen B. Indications that phototherapy is a risk factor for insulin-dependent diabetes. Diabetes Care. 2003;26(1):247-248.

20. Bauer J, Buttner P, Luther H, et al. Blue light phototherapy of neonatal jaundice does not increase the risk for melanocytic nevus development. Arch Dermatol. 2004;140(4):493-494.

21. Olah J, Toth-Molnar E, Kemeny L, et al. Long-term hazards of neonatal blue-light Phototherapy. Br J Dermatol. 2013;169(2):243-249. 